\title{
Budget Impact of Oral Semaglutide Intensification versus Sitagliptin among US Patients with Type 2 Diabetes Mellitus Uncontrolled with Metformin
}

\author{
Elizabeth Wehler ${ }^{1} \cdot$ Dominik Lautsch $^{2} \cdot$ Stacey Kowal ${ }^{1} \cdot$ Glenn Davies $^{2} \cdot$ Andrew Briggs $^{3} \cdot$ Qianyi Li $^{1}$. \\ Swapnil Rajpathak ${ }^{2} \cdot$ Adnan Alsumali $^{2}$
}

Accepted: 19 September 2020 / Published online: 5 November 2020

(c) The Author(s) 2020

\begin{abstract}
Background Oral semaglutide was approved in 2019 for blood glucose control in patients with type 2 diabetes mellitus (T2DM) and was the first oral glucagon-like peptide 1 receptor agonist (GLP-1 RA). T2DM is associated with substantial healthcare expenditures in the US, so the cost of a new intervention should be weighed against clinical benefits.

Objective This study evaluated the budget impact of a treatment pathway with oral semaglutide $14 \mathrm{mg}$ daily versus oral sitagliptin $100 \mathrm{mg}$ daily among patients not achieving target glycated hemoglobin (HbA1c) level despite treatment with metformin. Methods This study used the validated IQVIA ${ }^{\mathrm{TM}}$ CORE Diabetes Model to simulate the treatment impact of oral semaglutide $14 \mathrm{mg}$ and sitagliptin $100 \mathrm{mg}$ over a 5-year time horizon from a US healthcare sector (payer) perspective. Trial data (PIONEER 3) informed cohort characteristics and treatment effects, and literature sources informed event costs. Population and market share data were from the literature and data on file. The analysis evaluated the estimated budget impact of oral semaglutide $14 \mathrm{mg}$ use for patients currently using sitagliptin $100 \mathrm{mg}$ considering both direct medical and treatment costs to understand the impact on total cost of care, given underlying treatment performance and impact on avoidable events.

Results In a hypothetical plan of 1 million lives, an estimated 1993 patients were treated with sitagliptin $100 \mathrm{mg}$ in the target population. Following these patients over 5 years, the incremental direct medical and treatment costs of a patient using oral semaglutide $14 \mathrm{mg}$ versus sitagliptin $100 \mathrm{mg}$ was \$US16,562, a 70.7\% increase (year 2019 values). A hypothetical payer would spend an additional \$US3,300,143 (7.1\%) over 5 years for every $10 \%$ of market share that oral semaglutide $14 \mathrm{mg}$ takes away from sitagliptin $100 \mathrm{mg}$. Univariate and scenario analyses with alternate inputs and assumptions demonstrated consistent results.

Conclusions Use of oral semaglutide $14 \mathrm{mg}$ in patients currently receiving sitagliptin $100 \mathrm{mg}$ substantially increases the budget impact for patients with T2DM whose blood glucose level is not controlled with metformin over a 5-year time horizon for US healthcare payers.
\end{abstract}

\section{Plain Language Summary}

Patients with type 2 diabetes mellitus (T2DM) have many treatment options. Choices depend on factors such as cost, preference, and patient characteristics. Oral semaglutide was recently approved for the treatment of T2DM as the first oral therapy

Digital Features To view digital features for this article go to https://doi.org/10.6084/m9.figshare.12966854.

Electronic supplementary material The online version of this article (https://doi.org/10.1007/s40273-020-00967-7) contains supplementary material, which is available to authorized users.

Elizabeth Wehler

beth.wehler@iqvia.com

Extended author information available on the last page of the article 
of its class. This study estimated the cost for patients treated with sitagliptin $100 \mathrm{mg}$, a commonly used T2DM treatment, versus oral semaglutide $14 \mathrm{mg}$ for patients whose disease is not well controlled with metformin. Costs and effects were estimated over 5 years for each treatment strategy using predictive model equations and clinical trial data for the two treatments. These costs were considered for both a hypothetical healthcare plan of 1 million lives and the full US population. A patient treated with oral semaglutide $14 \mathrm{mg}$ would expect to see $70.7 \%$ higher costs than a patient treated with sitagliptin $100 \mathrm{mg}$ over 5 years. For every $10 \%$ of patients who would switch from sitagliptin $100 \mathrm{mg}$ to oral semaglutide $14 \mathrm{mg}$, costs would increase by $7.1 \%$. Changing the cost of oral semaglutide $14 \mathrm{mg}$ had the greatest impact on model results. The findings from the analysis were consistent across a range of alternate model inputs. Oral semaglutide $14 \mathrm{mg}$ is more costly than sitagliptin $100 \mathrm{mg}$ over 5 years.

\section{Key Points for Decision Makers}

Using clinical projections via the validated IQVIA ${ }^{\mathrm{TM}}$ CORE Diabetes Model in combination with a budget impact modeling approach, this study integrates information on how two oral products affect the patient journey in diabetes into an over-arching assessment of budget impact to understand the total cost-of-care implications for formulary decisions.

Over a 5-year time horizon, oral semaglutide $14 \mathrm{mg}$ was a more costly treatment strategy than sitagliptin $100 \mathrm{mg}$.

\section{Introduction}

Type 2 diabetes mellitus (T2DM) is a multifactorial disease characterized by an increased risk of obesity, macrovascular conditions such as cardiovascular disease, and microvascular disease that can lead to kidney failure, neuropathy, and blindness [1]. The latest report from the Centers for Disease Control and Prevention found that diabetes affected 30.3 million people in the USA in 2015, with $90-95 \%$ of these having T2DM [2]. This corresponds to a prevalence of diagnosed T2DM in the USA in 2016 of $8.6 \%$, or 21.0 million adults [3]. In addition to increased morbidity, mortality is higher for people with diabetes than for those without, and diabetes is among the leading causes of death in the USA, resulting in 252,806 (9.3\%) deaths in 2015 [2]. Diabetes is also the primary contributor to cardiovascular death, the top cause of death in the USA [4, 5].

The high prevalence and risk of complications/comorbidities associated with T2DM leads to a large economic burden on patients, the population, and health systems. Undiscounted diabetes medication spending in the USA increased from \$US33.7 billion in 2014 to 53.7 billion in 2017 [6]. The direct and indirect costs for people with diabetes account for about a quarter of healthcare dollars spent in the USA, with a total cost of diagnosed diabetes in 2017 of
\$US327 billion [7]. Care for a person with diabetes costs an average of $\$$ US16,752 per year [7, 8]. Among annual expenditures, hospitalization is a key driver of costs in patients with T2DM. A retrospective cohort analysis showed the mean 12-month all-cause medical costs to be \$US9624 for patients not incurring a hospitalization, \$US42,011 for those with an inpatient admission but no 30-day readmission, and \$US76,806 for patients with both an inpatient admission and 30-day readmission [9].

The key goal of diabetes management is to achieve glycemic control, which subsequently lowers the risk of complications, including cardiovascular protection, and improves quality of life $[10,11]$. The 2020 American Diabetes Association standards of care recommend a glycated hemoglobin (HbA1c) target of 6.5-8\%, depending on patient characteristics and history of hypoglycemia and adverse effects. A treatment switch threshold of $8 \%$ may be appropriate for patients with a history of severe hypoglycemia, limited life expectancy, or advanced cardiovascular complications for whom previous glucose-lowering agents have failed [10]. However, treatment switches at higher $\mathrm{HbA1c}$ values have been observed in the real-world setting. A study of more than 7000 patients with uncontrolled T2DM identified 44\% of patients not switching treatments at an $\mathrm{HbA1c}$ of $9 \%$ or even higher $[12,13]$.

Metformin is the preferred initial pharmacologic agent for patients diagnosed with T2DM whose HbA1c level is uncontrolled with lifestyle changes. If treatment goals are not met, further intensification should not be delayed [10]. In choosing add-on pharmacologic agents, a patient-centered approach is recommended that incorporates considerations for comorbidities, hypoglycemia risk, impact on weight, cost, risk of side effects, and patient preference [10]. In addition, the European Society of Cardiology also emphasizes a multifactorial management approach that integrates reduction in HbA1c, systolic blood pressure (SBP), and lipids, which decreases cardiovascular events [11]. Dipeptidyl peptidase-4 inhibitors (DPP-4i) are effective in lowering $\mathrm{HbA} 1 \mathrm{c}$ without increasing the risk of hypoglycemia or cardiovascular events $[14,15]$. Compounds with evidence to reduce cardiovascular events include sodium glucose 
cotransporter-2 inhibitors (SGLT-2i) and glucagon-like peptide-1 receptor agonists (GLP-1 RA), which are currently recommended as first-line therapy for patients with high cardiovascular risk, including nephropathy [10]. Yet, the oral formulation of semaglutide (a GLP-1 RA) failed to show an additional cardiovascular event reduction when tested versus the antihyperglycemic standard of care in a population of patients with T2DM and at high cardiovascular risk [16]. Other recommended T2DM therapies include sulfonylureas and thiazolidinedione, especially if cost is an issue [10]. A recent US study showed that sulfonylureas and DPP-4i were the most common second antidiabetic add-on treatment (46 and 20\%, respectively) [17]. However, the use of sulfonylureas and thiazolidinedione has decreased over time, whereas the use of DPP-4i has increased from $6.2 \%$ in 2008 to $12.4 \%$ in 2015 [18].

With oral semaglutide being the first oral GLP-1 RA available to patients with T2DM, it is important to understand the comparative performance beyond the trial, including the impact on patients' risk for avoidable events and total cost of care [19]. Comparative value assessments are needed to provide a more comprehensive picture of incremental value and inform healthcare decision making and resource allocation across healthcare systems. Oral semaglutide ( $3 \mathrm{mg}, 7 \mathrm{mg}$, and $14 \mathrm{mg}$ ) has been directly compared with relevant doses of empagliflozin, sitagliptin, and liraglutide in clinical trials with patients with T2DM uncontrolled with metformin, sulfonylureas, and/or SGLT-2i [20-23]. In the clinical trials PIONEER 3 and PIONEER 7, oral semaglutide $14 \mathrm{mg}$ statistically significantly reduced $\mathrm{HbA} 1 \mathrm{c}$ compared with sitagliptin $100 \mathrm{mg}$ (PIONEER 3: - 1.3\% oral semaglutide $14 \mathrm{mg}$ vs. $-0.8 \%$ sitagliptin over 26 weeks; PIONEER
7: $-1.3 \%$ oral semaglutide flexible dose vs. $-0.8 \%$ sitagliptin over 52 weeks) [22, 23]. To date, a budget impact assessment on the impact of oral semaglutide $14 \mathrm{mg}$ for patients for whom metformin fails in the USA is lacking.

As new T2DM treatments displace current therapies, it is important to consider the financial impact of this tradeoff. Sitagliptin $100 \mathrm{mg}$ was selected as the comparator of interest because it has the same oral mode of administration and head-to-head evidence versus oral semaglutide $14 \mathrm{mg}$ is available. Manufacturer data on file and the literature indicate that DPP-4i are commonly used as second-line treatments, and sitagliptin $100 \mathrm{mg}$ represents the majority of DPP-4i use [17]. A budget-impact analysis was conducted to understand the total direct medical cost tradeoff associated with switching patients from sitagliptin $100 \mathrm{mg}$ to oral semaglutide $14 \mathrm{mg}$ in second-line T2DM from a healthcare sector perspective.

\section{Methods}

\subsection{Budget-Impact Model (BIM) Framework}

This budget-impact model (BIM) used a comparative cost determination framework to compare patients currently treated with sitagliptin $100 \mathrm{mg}$ and patients with oral semaglutide $14 \mathrm{mg}$ uptake. The analysis utilized the IQVIA ${ }^{\mathrm{TM}}$ Core Diabetes Model (CDM) v9.0 to estimate clinical outcomes and direct medical costs to allow for estimation of budget impact and total cost of care given relative clinical performance. The output from the CDM was incorporated into the BIM, which considered the number of patients
Step 1: CDM Outcome Generation

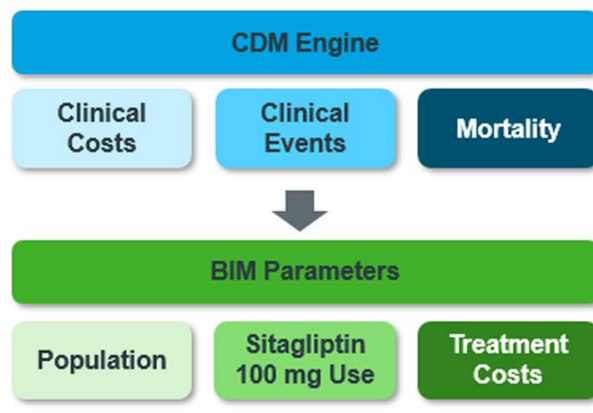

Step 2: BIM Cost Determination Framework

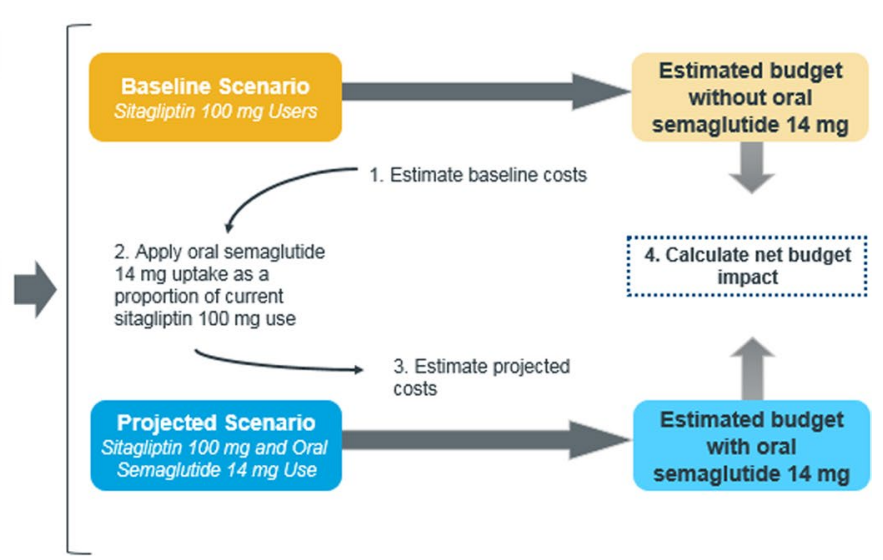

Fig. 1 Model structure. This figure displays how the CDM incorporates clinical outcomes (e.g. costs, events, mortality), which feed into the underlying BIM structure to produce the budget impact analysis results. BIM budget impact model, CDM Core Diabetes Model 
currently receiving sitagliptin $100 \mathrm{mg}$ for uncontrolled blood glucose on metformin and the financial impact of new oral semaglutide $14 \mathrm{mg}$ use in this population. Patients were allowed to exit the cohort because of mortality based on the CDM output (Fig. 1).

\subsection{IQVIA ${ }^{\mathrm{Tm}}$ Core Diabetes Model (CDM)}

The IQVIA ${ }^{\mathrm{TM}} \mathrm{CDM}$ is an internet application that can assess the long-term clinical and cost impacts of diabetes interventions. The model includes 17 sub-models for diabetes complications using a combination of semi-Markov structures and Monte Carlo simulations, which uses data on $\mathrm{HbA} 1 \mathrm{c}$ and other physiological impacts to predict events over time. Information on the model has been extensively published, along with robust validation exercises, including internal and external validation [24-26]. This analysis used the most recently published UKPDS (UK Prospective Diabetes Study) T2DM risk equations for HbA1c progression and mortality (UKPDS82), a long-term follow up of a large patient cohort of patients with T2DM [27]. Simulations were run for 5 years to reflect the recommended time horizon for BIMs, using a theoretical cohort of 1000 patients run for 1000 simulations [28]. Costs were reported in \$US, year 2019 values, and no discounting was included, based on best practices [28].

\subsection{Model Inputs: CDM}

\subsubsection{Baseline Characteristics}

The PIONEER 3 study provided a head-to-head comparison of oral semaglutide ( $3 \mathrm{mg}, 7 \mathrm{mg}$, and $14 \mathrm{mg}$ ) versus sitagliptin $100 \mathrm{mg}$ in adults with T2DM uncontrolled under metformin [22]. The model cohort used the patient characteristics reported in PIONEER 3, a weighted average across treatment arms, aligning with the population from which clinical efficacy was derived for both oral semaglutide and sitagliptin. Patient characteristics required by the CDM but not available from the PIONEER 3 publication were informed by the VERTIS FACTORIAL study, which investigated the efficacy of sitagliptin + ertugliflozin versus each compound individually upon metformin failure [29]. The overlapping baseline characteristics between these two studies were generally consistent and appropriate for patients at this line of therapy. Key baseline characteristics are presented in Table 1, with full data available in Table 1 in the electronic supplementary material (ESM).

\subsubsection{Intervention Effects}

The base-case analysis compared two treatment pathways for the target population (Fig. 1 in the ESM). Patients in treatment pathway 1 initiated treatment with oral semaglutide
Table 1 Key cohort and treatment cost inputs

\begin{tabular}{lcc}
\hline Characteristics & Value & Reference \\
\hline Baseline characteristics & & \\
Start age, years & 57.75 & {$[22]$} \\
Duration of diabetes, years & 8.55 & {$[22]$} \\
$\%$ Male & 52.8 & {$[22]$} \\
HbA1c, $\%$ & 8.33 & {$[22]$} \\
SBP, mmHg & 134.00 & {$[22]$} \\
DBP, mmHg & 80.50 & {$[22]$} \\
TC, mg/dL & 173.42 & {$[22]$} \\
HDL-C, mg/dL & 44.53 & {$[22]$} \\
LDL-C, mg/dL & 92.26 & {$[22]$} \\
TG, mg/dL & 156.26 & {$[22]$} \\
BMI, kg/m ${ }^{2}$ & 32.50 & {$[22]$} \\
eGFR, mL/min/1.73 m ${ }^{2}$ & 95.75 & {$[22]$} \\
Annual treatment costs; $\$$ US, year 2019 values & & \\
Metformin + oral semaglutide & 6110.99 & {$[22,34,35]$} \\
Metformin + oral semaglutide + insulin glargine & $11,391.15$ & {$[30,31,34,35]$} \\
Metformin + sitagliptin & 1586.76 & {$[22,34,35]$} \\
Metformin + sitagliptin + insulin glargine & 6866.92 & {$[30,34,35]$} \\
Metformin + insulin glargine + bolus insulin & 8399.04 & {$[22,30,34,37]$} \\
\hline
\end{tabular}

$B M I$ body mass index, $D B P$ diastolic blood pressure, $e G F R$ estimated glomerular filtration rate, HbAlc glycated hemoglobin, $H D L-C$ high-density lipoprotein cholesterol, $L D L-C$ low-density lipoprotein cholesterol, $S B P$ systolic blood pressure, $T C$ total cholesterol, $T G$ triglycerides 
Table 2 Treatment effect

\begin{tabular}{|c|c|c|c|c|c|c|c|}
\hline \multirow[t]{2}{*}{ Therapy } & \multicolumn{3}{|c|}{ Primary intervention } & \multicolumn{3}{|l|}{ Insulin glargine } & \multirow{2}{*}{$\begin{array}{l}\text { Insulin glar- } \\
\text { gine + bolus } \\
\text { MET + IG + bolus } \\
\text { insulin }^{\mathrm{a}}[32,33]\end{array}$} \\
\hline & $\begin{array}{l}\text { MET + oral } \\
\text { SEM } 14 \mathrm{mg} \\
{[22]}\end{array}$ & $\begin{array}{l}\text { MET + SIT } \\
100 \mathrm{mg} \\
{[22]}\end{array}$ & $\begin{array}{l}\text { Weighted oral } \\
\operatorname{SEM}^{\mathrm{a}}[22,23]\end{array}$ & $\begin{array}{l}\text { MET + oral SEM } \\
14 \mathrm{mg}+\mathrm{IG}[30, \\
31]\end{array}$ & $\begin{array}{l}\text { MET + SIT } \\
100 \mathrm{mg}+\mathrm{IG} \\
{[30,31]}\end{array}$ & $\begin{array}{l}\mathrm{MET}+\mathrm{IG}^{\mathrm{a}}[30, \\
31]\end{array}$ & \\
\hline HbA1c, \% & -1.300 & -0.800 & -1.142 & -1.300 & -1.880 & -1.420 & -1.500 \\
\hline SBP, mmHg & -3.000 & -2.000 & -2.820 & -0.440 & -0.440 & 0.590 & 0.000 \\
\hline $\mathrm{DBP}, \mathrm{mmHg}$ & -1.000 & 0.000 & -1.000 & -0.303 & -0.303 & -0.870 & 0.000 \\
\hline $\mathrm{TC}, \mathrm{mg} / \mathrm{dL}$ & -5.196 & 0.000 & -4.193 & -2.280 & -2.280 & -1.760 & 0.000 \\
\hline LDL-C, mg/dL & -1.837 & 1.863 & -1.216 & -0.536 & -0.536 & 0.167 & 0.000 \\
\hline HDL-C, mg/dL & -0.898 & -0.444 & -0.794 & 1.280 & 1.280 & 1.450 & 0.000 \\
\hline $\mathrm{TG}, \mathrm{mg} / \mathrm{dL}$ & -12.522 & -4.701 & -9.553 & -18.250 & -18.250 & -20.270 & 0.000 \\
\hline BMI, $\mathrm{kg} / \mathrm{m}^{2}$ & -1.100 & -0.200 & -0.942 & 0.560 & 0.560 & 0.620 & 1.270 \\
\hline $\begin{array}{l}\text { eGFR, mL/ } \\
\mathrm{min} / 1.73 \mathrm{~m}^{2}\end{array}$ & -1.900 & -2.880 & -1.822 & 1.430 & 1.430 & 0.540 & 0.000 \\
\hline NSHE & 40.860 & 31.330 & 38.764 & 145.430 & 145.430 & 180.660 & 784.430 \\
\hline $\begin{array}{l}\text { SHE, non-medical } \\
\text { assistance }\end{array}$ & 15.054 & 15.021 & 13.099 & 9.110 & 9.110 & 31.340 & 0.000 \\
\hline $\begin{array}{l}\text { SHE, medical } \\
\text { assistance }\end{array}$ & 0.430 & 1.717 & 0.255 & 0.460 & 0.460 & 0.000 & 0.000 \\
\hline
\end{tabular}

$B M I$ body mass index, $D B P$ diastolic blood pressure, $e G F R$ estimated glomerular filtration rate, $H b A l c$ glycated hemoglobin, $H D L-C$ high-density lipoprotein cholesterol, $I G$ insulin glargine, $L D L-C$ low-density lipoprotein cholesterol, $M E T$ metformin, $N S H E$ non-severe hypoglycemic event, $S B P$ systolic blood pressure, SEM semaglutide, $S H E$ severe hypoglycemic event, SIT sitagliptin, $T C$ total cholesterol, $T G$ triglycerides

${ }^{a}$ Treatments used in scenario analyses

$14 \mathrm{mg}$ on top of background metformin (metformin + oral semaglutide $14 \mathrm{mg}$ ), and patients in pathway 2 initiated sitagliptin $100 \mathrm{mg}$ treatment on top of background metformin (metformin + sitagliptin $100 \mathrm{mg}$ ). The treatment effect for each arm was informed by the PIONEER 3 study and was applied upon model initiation [22] (Table 2).

When patients' HbA1c exceeded 8\%, basal insulin (insulin glargine) was added to the initial treatment (Pathway 1: metformin + oral semaglutide $14 \mathrm{mg}+$ insulin glargine; Pathway 2: metformin + sitagliptin $100 \mathrm{mg}+$ insulin glargine). The effect of metformin + sitagliptin $100 \mathrm{mg}$ + insulin glargine was based on the intervention arm of the CompoSIT I study [30] (Table 2). Data for the treatment effect of insulin glargine when added to metformin + oral semaglutide $14 \mathrm{mg}$ were limited. The PIONEER 8 study [31] reported the HbA1c and hypoglycemia rate of oral semaglutide $14 \mathrm{mg}$ when used with insulin. HbA1c from this study was used for the insulin glargine step for the oral semaglutide $14 \mathrm{mg}$ pathway. The definition of hypoglycemic events differed between CompoSIT I and PIONEER 8. Additionally, when mapping the PIONEER 8 data to fields in the CDM, the event rate derived was notably higher than when using CompoSIT I. To be conservative, and given the expectation that hypoglycemic events should not be notably different, the hypoglycemia rates from CompoSIT I were used for metformin + oral semaglutide $14 \mathrm{mg}+$ insulin glargine. Other missing parameters from PIONEER 8 were assumed equal to those from CompoSIT I.

A scenario analysis has patients switch treatments more quickly when patients' HbA1c exceeded the threshold of $7 \%$. In this case, patients add bolus insulin while dropping the primary therapy (e.g., oral semaglutide or sitagliptin). Efficacy of metformin + insulin glargine + bolus insulin was based on the DUAL VII study and the GINGER study [32, 33] (Table 2).

Treatment effects on cardiovascular outcomes beyond predictions from the model risk equations were excluded from the base case for several reasons: (1) cardiovascular outcomes trials (CVOTs) for both oral semaglutide $14 \mathrm{mg}$ and sitagliptin $100 \mathrm{mg}$ showed nonsignificant treatment effects in established cardiovascular populations; (2) CVOT populations were distinctly different from the PIONEER 3 population; (3) these effects were not studied in head-tohead trials $[15,16]$. However, the impact of treatment on cardiovascular outcomes are implicitly captured within the risk equations used in the CDM. In addition, a scenario analysis tests the point estimates of the hazard ratios for cardiovascular events relative to placebo for the initial step in therapy from the CVOT studies. 


\subsubsection{Costs}

Unit costs of treatments were based on wholesale acquisition costs (WAC) from the MediSpan PriceRx database, using the least expensive option if multiple forms were available [34]. Net costs of oral semaglutide $14 \mathrm{mg}$ and sitagliptin $100 \mathrm{mg}$ were used to reflect cost of drugs in practice, assumed to be a $35.1 \%$ discount for oral semaglutide $14 \mathrm{mg}$ (based on the discount for injectable semaglutide) and a $72.6 \%$ discount for sitagliptin $100 \mathrm{mg}$ based on the recently published Institute for Clinical and Economic Review assessment of oral semaglutide [35].

Dosing for each regimen reflects the prescribing information, except for insulin, which is patient specific [36]. The daily insulin glargine dose of 53.2 IU/day was applied when insulin glargine was used in combination with sitagliptin $100 \mathrm{mg}$, based on the intervention arm of CompoSIT I [30]. Given that this dose is similar to the baseline insulin dose (54 IU/day) in PIONEER 8, the same dose was applied to the metformin + oral semaglutide $14 \mathrm{mg}+$ insulin glargine combination. In a scenario analysis, a daily insulin glargine dose of $61.3 \mathrm{IU} /$ day was applied when insulin glargine was used with bolus insulin, based on the comparator arm of CompoSIT I [30]. Dosage for bolus insulin (represented by insulin aspart) was calculated assuming 0.2 units $/ \mathrm{kg}$ [37] and the average patient weight derived from PIONEER 3 (18.2 IU/day) [22].

Costs of test strips, lancets, and needles were considered for insulin regimens. Patients on insulin regimens were assumed to use one lancet and 2.7 test strips per day, with those on insulin glargine + bolus insulin requiring an additional two needles [38]. Unit costs were sourced from the ADW website [39] and the Centers for Medicaid and Medicare Services durable medical equipment file [40].

Dosing, unit cost, and resource use were combined to generate annual costs for each treatment (Table 1). T2DM management costs were based on the literature, PriceRx, and Medicare fee schedules [34, 41-45] (Table 2 in the ESM).

\subsection{Model Inputs-BIM}

\subsubsection{Population}

The budget-impact analysis considered the number of patients who would be eligible for oral semaglutide $14 \mathrm{mg}$ in the second-line T2DM population. A hypothetical plan size of 1 million lives was assumed, and the following steps were applied to arrive at the eligible population: proportion of the population who are adults $(77.8 \%)$, T2DM prevalence among adults in the USA (8.6\%), proportion of patients with T2DM who receive metformin $(41.0 \%)$, and proportion for whom metformin has failed $(48.0 \%)$ [ 17 , 46-48]. A scenario analysis considered the full US population, estimated at 332,639,000 for the year 2020, with the same steps applied in a top-down population cascade [46] (Table 3).

\subsubsection{Market Shares}

A recent retrospective database analysis found that $20 \%$ of second-line patients with T2DM used DPP-4i [17]. Based on manufacturer data on file, sitagliptin $100 \mathrm{mg}$ represents $75.7 \%$ of the overall DPP-4i utilization in the USA. Uptake assumptions for oral semaglutide $14 \mathrm{mg}$ included $14 \%, 25 \%$, $50 \%, 75 \%$, and $100 \%$ of the current sitagliptin $100 \mathrm{mg}$ share [35].

\subsection{Scenario Analyses}

Scenario analyses were performed with alternative input values and assumptions to assess the robustness of model results given underlying uncertainty, including weighted dose-specific oral semaglutide treatment effect using the dose distribution from the PIONEER 7 trial [23], using alternative assumptions for the metformin + oral semaglutide $14 \mathrm{mg}+$ insulin glargine step, varying the oral semaglutide $14 \mathrm{mg}$ price, incorporating different therapy

Table 3 Population inputs

\begin{tabular}{lrlrc}
\hline Input & $\%$ & Hypothetical plan $^{\mathrm{a}}$ & US population $^{\mathrm{a}}$ & References $^{\text {Und }}$ \\
\hline Total population & & $1,000,000$ & $332,639,000$ & {$[46]$} \\
Percentage adults & 77.8 & 777,648 & $258,676,000$ & {$[46]$} \\
T2DM prevalence & 8.6 & 66,878 & $22,246,136$ & {$[47]$} \\
Percentage treated with metformin & 41.0 & 27,420 & $9,120,916$ & {$[48]$} \\
Percentage failed metformin therapy & 48.0 & 13,162 & $4,378,040$ & {$[17]$} \\
Percentage treated with DPP-4i & 20.0 & 2623 & 875,608 & {$[17]$} \\
Percentage receiving sitagliptin & 75.7 & 1993 & 662,835 & $\begin{array}{c}\text { Manufac- } \\
\text { turer data } \\
\end{array}$ \\
& & & & on file \\
\hline
\end{tabular}

$D P P-4 i$ dipeptidyl peptidase- 4 inhibitor, $T 2 D M$ type 2 diabetes mellitus

${ }^{a}$ Amounts may not sum because of rounding 


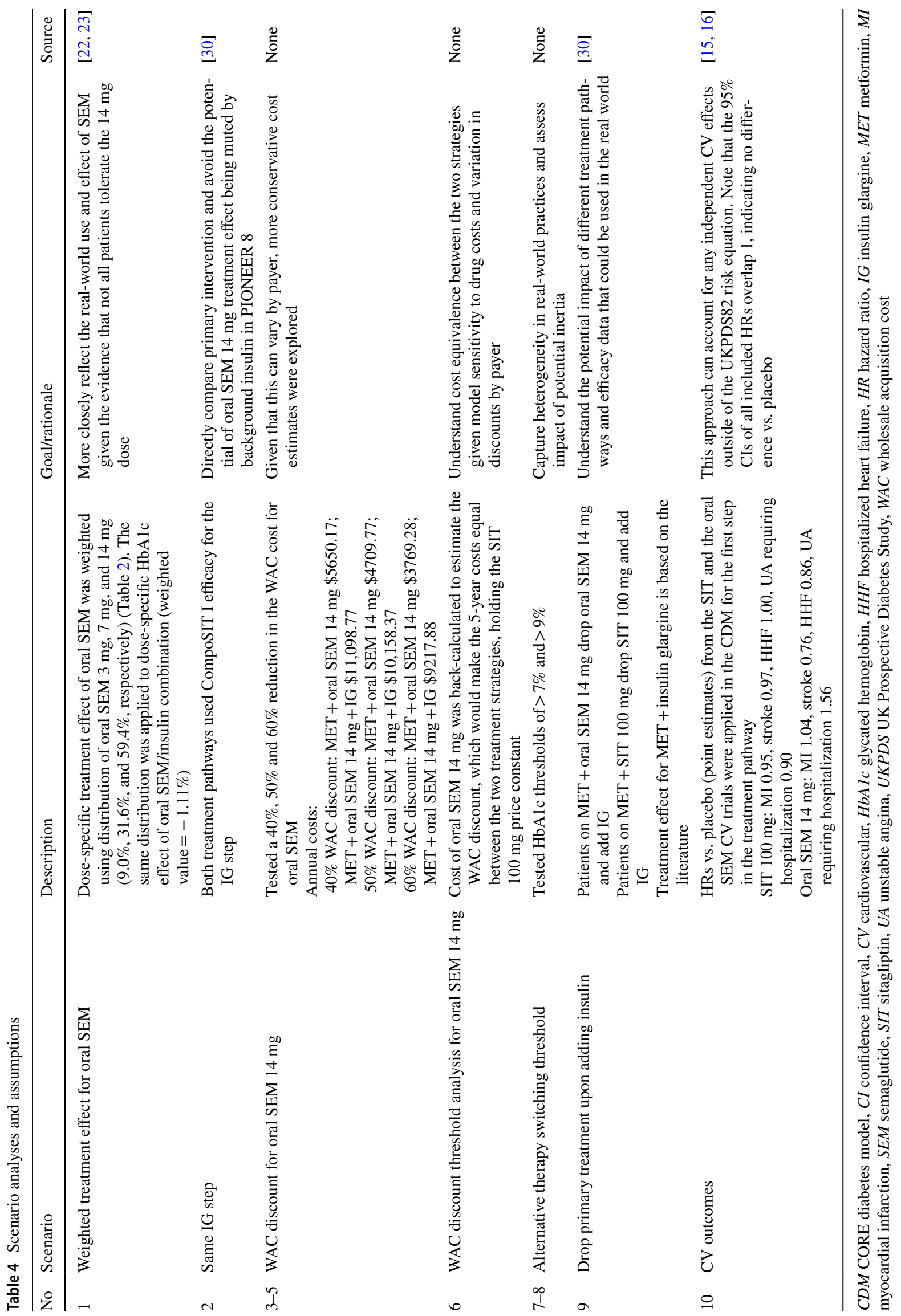


switching thresholds, assuming patients drop their primary therapy (oral semaglutide $14 \mathrm{mg}$ or sitagliptin $100 \mathrm{mg}$ ) upon adding insulin glargine, and independent cardiovascular effects. These scenarios were selected based on uncertainty around key inputs and assumptions (Table 4).

\section{Results}

\subsection{Base-Case Results}

In a hypothetical 1 million lives plan, 13,162 patients would be eligible for oral semaglutide $14 \mathrm{mg}$ in the second-line T2DM population, with 1993 patients currently receiving sitagliptin $100 \mathrm{mg}$. If extrapolated to the US population, 4,378,040 patients would be eligible for oral semaglutide $14 \mathrm{mg}$, with 662,835 receiving sitagliptin $100 \mathrm{mg}$ (Table 3).

The average patient treated with the oral semaglutide $14 \mathrm{mg}$ pathway was estimated to incur \$US39,997 in direct healthcare costs (medical and pharmacy) over 5 years, compared with \$US23,436 for the average patient treated with the sitagliptin $100 \mathrm{mg}$ pathway, an incremental cost per patient of \$US16,562 (70.7\% increase) (Table 5). Diabetes therapy costs represented the largest cost component in each pathway (86.6 and 76.7\%, respectively), followed by cardiovascular, other direct medical, and hypoglycemia costs. The cumulative incidence of clinical events was consistent across the two treatment strategies (Table 3 in the ESM). Results were driven by substantial differences in diabetes therapy costs. Over the 5-year time horizon, oral semaglutide $14 \mathrm{mg}$ represented the bulk of these costs in the pathway, followed by basal insulin and metformin $(85.1 \%, 14.8 \%$, and $0.1 \%$, respectively), whereas basal insulin constituted the majority of these costs in the sitagliptin $100 \mathrm{mg}$ pathway $(42.4 \%$ for sitagliptin $100 \mathrm{mg}, 57.4 \%$ for basal insulin, and $0.2 \%$ for metformin). While Oral semaglutide $14 \mathrm{mg}$ is associated with a larger $\mathrm{HbA1c}$ decrease at treatment initiation $(-1.30$ vs. -0.88$)$, the annual cost of oral semaglutide $14 \mathrm{mg}$ is substantially higher than for sitagliptin $100 \mathrm{mg}$. Patients on sitagliptin $100 \mathrm{mg}$ add insulin glargine a year earlier than those on oral semaglutide $14 \mathrm{mg}$ (year 4 vs. year 5), which results in a drop in HbA1c but higher diabetes therapy costs in year 4. Minimal differences in the remaining costs were seen given (1) the relatively healthy patient profile of the population, based on PIONEER 3 and VERTIS FACTORIAL, including low rates of cardiovascular disease (CVD) at baseline [22, 29] and (2) that the 5-year time horizon does not capture lifetime impacts of treatment, which may lead to greater differences between treatments. However, even with a longer time horizon, all patients would move to the

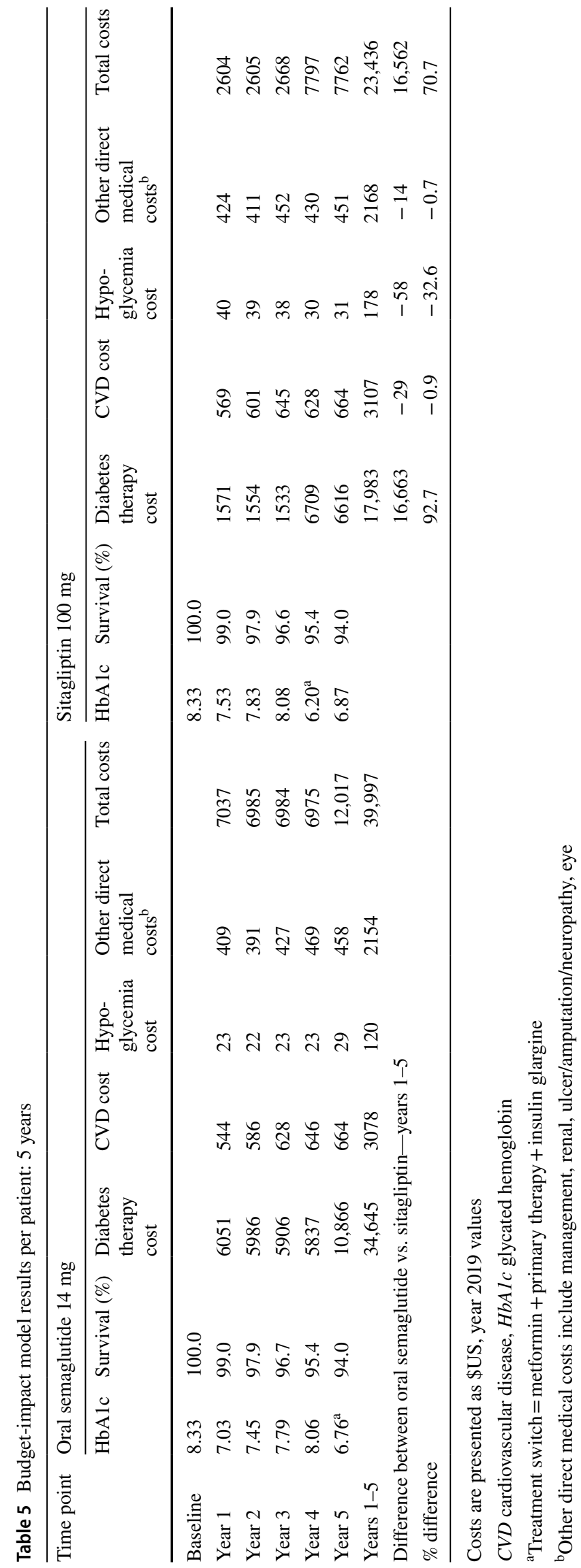


same third treatment in the sequence (metformin + insulin glargine + bolus insulin).

Extrapolating the model results to the population level, a hypothetical plan of 1 million lives over 5 years would incur a direct healthcare cost of \$US46,698,940 (Table 4 in the ESM). If oral semaglutide $14 \mathrm{mg}$ is used for $14 \%$ of these patients (279 of 1993 patients on sitagliptin $100 \mathrm{mg}$ ), as presented in the Institute for Clinical and Economic Review report from their threshold analysis, the 5-year direct healthcare cost rises to $\$$ US51,319,140, an incremental cost increase of $9.9 \%$ (\$US4,620,201, or \$US0.08 per member per month [PMPM]) (Fig. 2). For every 10\% market share that oral semaglutide $14 \mathrm{mg}$ takes away from sitagliptin $100 \mathrm{mg}$, the hypothetical payer would spend \$US3,300,143 (7.1\%) more over 5 years. When extrapolating to the US population, this value increases to $\$ U S 1,097,756,401$ over 5 years.

\subsection{Scenario Results}

Scenario analyses did not alter the conclusions of the basecase analysis (Fig. 3). The cost of oral semaglutide $14 \mathrm{mg}$ was the largest driver of results (scenarios 3-5), with discounts leading to reduced diabetes therapy costs for oral semaglutide $14 \mathrm{mg}$ over 5 years (incremental cost [\% change vs. base case] - 40\% discount: \$US14,335 [-13.4\%]; 50\% discount: \$US9792 [-40.9\%]; 60\% discount: \$US5249 $[-68.3 \%])$. A threshold analysis found that a $71.6 \%$ WAC discount would be required for oral semaglutide $14 \mathrm{mg}$ to generate 5-year per-patient costs equal to those of the sitagliptin $100 \mathrm{mg}$ pathway (scenario 6).

Use of alternate $\mathrm{HbA} 1 \mathrm{c}$ switching thresholds had a more notable impact on results (scenarios 7 and 8). A 7\% switching threshold caused patients in both pathways to add insulin glargine at year 2 and to add bolus insulin and drop

Fig. 2 5-year incremental budget impact analysis results for hypothetical 1 million lives plan. $P M P M$ per member per month
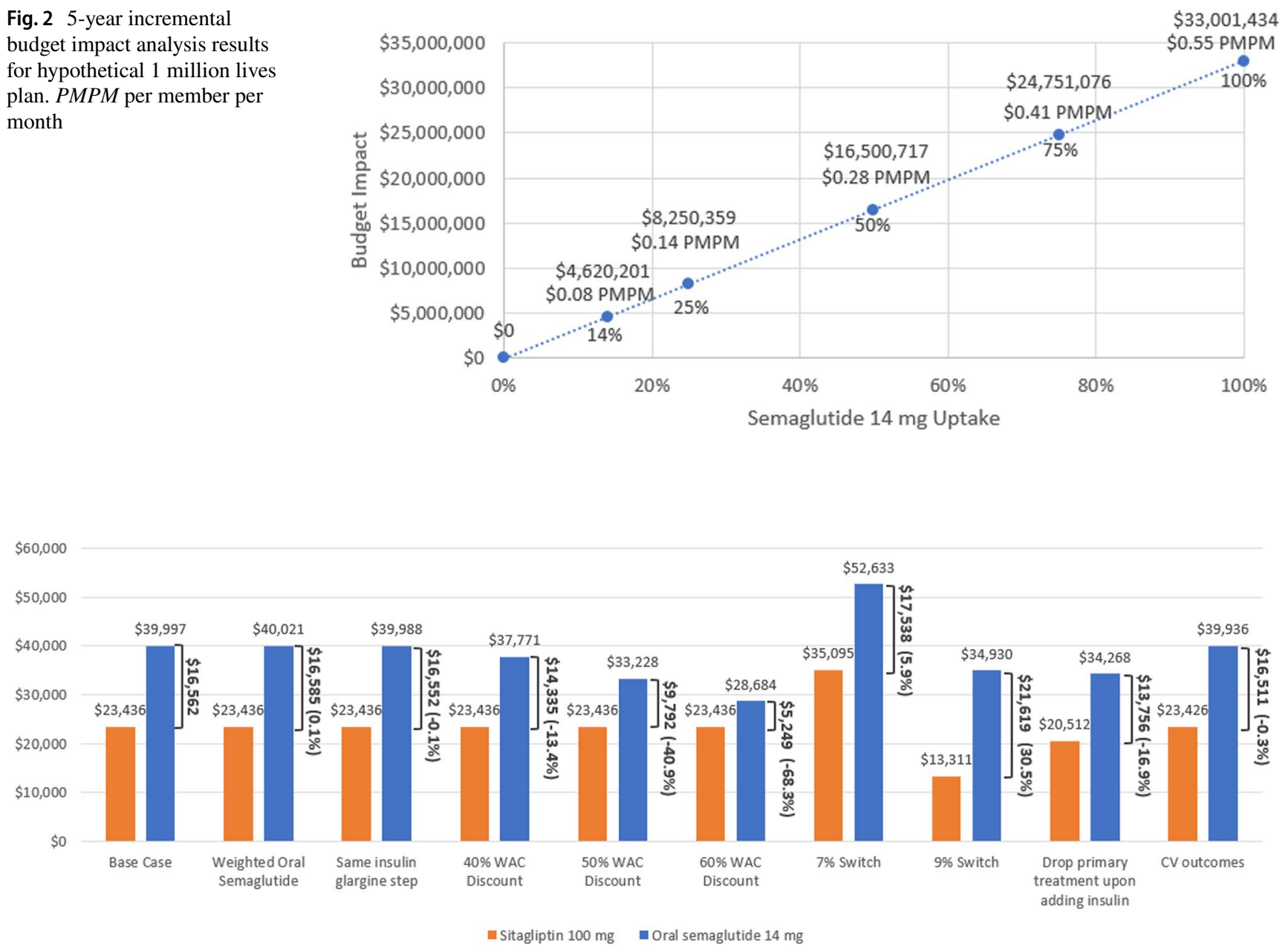

Fig. 3 5-year per-patient costs-scenario results. Values in bold are the 5-year incremental difference per patient (\% increase/decrease vs. the base case); Scenario 6 (WAC discount threshold analysis) is not included here as both the oral semaglutide $14 \mathrm{mg}$ and sitagliptin $100 \mathrm{mg}$ costs per patient are equal. $C V$ cardiovascular, WAC wholesale acquisition cost 
their primary therapy in year 5, leading to better clinical performance with lower $\mathrm{HbA1c}$, along with higher diabetes therapy costs (incremental cost [\% change vs. base case]: \$US17,539 [5.9\%]). Use of a 9\% switching threshold caused patients to stay on their primary therapy for the duration of the analysis, resulting in an incremental cost per patient over 5 years of \$US21,619, a 30.5\% increase from the base case.

When patients drop their primary therapy upon switching to insulin (scenario 9), diabetes therapy costs decrease in both pathways, with an incremental cost per patient over 5 years of $\$ \mathrm{US} 13,756$ (16.9\% reduction vs. the base case). The reduction is larger in the oral semaglutide $14 \mathrm{mg}$ pathway given the higher cost versus sitagliptin $100 \mathrm{mg}$.

The remaining scenarios had a limited impact on results. Use of the weighted treatment effect for oral semaglutide reduced the change in $\mathrm{HbA} 1 \mathrm{c}$ from 1.30 to $1.11 \%$, increasing CVD and other direct medical costs while decreasing diabetes therapy costs for the oral semaglutide pathway, producing a total cost difference of $\$ \mathrm{US} 16,585$ over 5 years ( $0.1 \%$ increase from base case). Using the same insulin glargine efficacy improved clinical performance, but as patients were only on this therapy for a year, the impact was minimal (incremental cost of $\$ \mathrm{US} 16,552 ; 0.1 \%$ decrease from base case). Including the point estimates of the hazard ratios for cardiovascular events relative to placebo for the initial step in therapy only led to a $0.31 \%$ reduction in the incremental cost over 5 years for a patient treated with sitagliptin $100 \mathrm{mg}$ versus oral semaglutide $14 \mathrm{mg}$ compared with the base case.

\section{Discussion}

The analysis indicated that, for patients moving onto secondline therapy, intensification with oral semaglutide $14 \mathrm{mg}$ is more costly than sitagliptin $100 \mathrm{mg}$. For the average patient treated with sitagliptin $100 \mathrm{mg}$, a payer would spend an additional \$US16,562 over 5 years if that patient was instead treated with oral semaglutide $14 \mathrm{mg}$. With oral semaglutide $14 \mathrm{mg}$ uptake ranging from 14 to $100 \%$, the PMPM budget impact would be \$US0.08-0.55, translating to $\$$ US1,536,858,962-10,977,564,012 for the US population.

These results were conservative for several reasons. First, the analysis assumed oral semaglutide patients would receive $14 \mathrm{mg}$. However, considering titration and the outcomes in PIONEER 7, which applied a flexible dose-adjustment approach to mimic individualized treatment in clinical practice, the actual treatment effect is likely to be lower [23]. The weighted oral semaglutide scenario accounted for this and produced a slightly higher budget impact compared with the base case $(0.14 \%)$. Second, the HbA1c target can be higher for patients in worse health [10], and patient inertia could also delay switching, leaving patients on each treatment step for longer.
The Institute for Clinical and Economic Review assessed the budget impact of oral semaglutide $14 \mathrm{mg}$ versus different classes of treatments using their cost-effectiveness analysis (CEA) as the underlying engine, a similar approach to this analysis [35]. Like the CDM, their model was a patientlevel microsimulation using the UKPDS82 risk equations. The BIM considered a combined market basket of DPP-4i, GLP-1 RA, and SGLT-2i and found an incremental cost per patient of \$US2600 for oral semaglutide when using net prices and considering prevalent patients. The analysis did not directly evaluate patients treated with sitagliptin $100 \mathrm{mg}$ and their potential switch to oral semaglutide but found in the CEA that the intervention costs for oral semaglutide represented the bulk of cost differences (\$US41,023, or 89\% of total oral semaglutide costs).

A recently published study evaluated the cost per patient achieving HbA1c treatment target with oral semaglutide $14 \mathrm{mg}$, concluding that oral semaglutide $14 \mathrm{mg}$ brought patients to an $\mathrm{HbA} 1 \mathrm{c}$ treatment target at a lower cost versus sitagliptin $100 \mathrm{mg}$ over a 1-year time horizon [49]. The analysis considered four different efficacy metrics, which incorporated $\mathrm{HbAlc}$ and information on weight loss/gain and hypoglycemia. Additionally, the study included WAC costs and did not consider likely discounts as seen by US payers. The evaluation applied a simple metric by dividing the 1 -year treatment cost by the proportion of patients achieving target and calculated the relative difference between treatments. The study translated key clinical outcomes into an easy-to-interpret cost/benefit metric based on the cost of the drug over 1 year compared with this analysis, which incorporated the modeling of future clinical impacts and treatment sequences. Key limitations included the use of $\mathrm{HbAlc}$ as a way to simplify the impact of treatment on T2DM and the use of the most efficacious dose $(14 \mathrm{mg})$, which likely overestimates oral semaglutide performance [23]. As only drug costs were included, the analysis was not comprehensive, with results being very sensitive to both costs and time frame. Additionally, no scenario analyses were conducted outside of a probabilistic sensitivity analysis.

Our analysis provides an appropriate approach to evaluate the budget impact of oral semaglutide $14 \mathrm{mg}$ as it incorporated treatment efficacy and disease management costs. Simulation models leveraging risk equations allow representative disease progression modeling for a multifactorial condition such as T2DM. Treatment sequences are considered to reflect how therapies are used in real-world practice.

As with all modeling analyses, this analysis has limitations that should be considered when interpreting the results. First, to best align with the source for treatment efficacy, the baseline cohort characteristics followed the PIONEER 3 publication, with data gaps filled by using another clinical trial for the same target population. Although data came from two sources, a comparison of baseline parameters 
available from both studies indicated consistency in patient characteristics. Additionally, the studies included patients with T2DM with low rates of cardiovascular events, which may not reflect the real-world population. Second, PIONEER 3 reported data for the three doses of oral semaglutide, but the $14 \mathrm{mg}$ arm was used to inform our base-case efficacy. PIONEER 7 showed that patients could not always up-titrate or tolerate the highest dose, and the weighted efficacy scenario found a small cost increase versus the base case. Third, there is no direct comparison of oral semaglutide $14 \mathrm{mg}$ and sitagliptin $100 \mathrm{mg}$ when they are used in combination with insulin glargine. Evidence is available for treatment efficacy and safety to compare metformin + sitagliptin $100 \mathrm{mg}+$ insulin glargine versus metformin + insulin glargine among patients for whom dual therapy with metformin and sitagliptin $100 \mathrm{mg}$ failed. However, no study with the desired sequence of therapy was available for oral semaglutide $14 \mathrm{mg}$. The total hypoglycemic event rate is higher with oral semaglutide $14 \mathrm{mg}$ based on PIONEER 3 , so the assumption that the metformin + oral semaglutide $14 \mathrm{mg}+$ insulin glargine combination is associated with the same hypoglycemic event rate as metformin + sitagliptin $100 \mathrm{mg}+$ insulin glargine could skew the results in favor of oral semaglutide $14 \mathrm{mg}$. The basal insulin combination study for subcutaneous semaglutide was considered inappropriate for use in this analysis, and there is considerable difference between oral and subcutaneous semaglutide HbA1c efficacy $[31,50]$. Fourth, the cardiovascular impacts of T2DM therapies have garnered increased interest [10, 51-53]. Direct cardiovascular effect was not incorporated in the base case because of a lack of direct evidence between oral semaglutide $14 \mathrm{mg}$ and sitagliptin $100 \mathrm{mg}$. However, both have demonstrated some cardiovascular protective effects in other trials, though with confidence intervals for key outcomes overlapping. The scenario included in the analysis using hazard ratio point estimates versus placebo from the CVOTs found a minimal impact on model results $[15,16]$. Even when the $95 \%$ confidence interval of the hazard ratios for oral semaglutide $14 \mathrm{mg}$ and sitagliptin $100 \mathrm{mg}$ is used in the analysis, the incremental cost over 5 years ranged from -0.45 to $0.41 \%$ versus the base case. Additional evidence is needed to allow more definitive conclusions on cardiovascular outcomes. Fifth, the impact of medication adherence was not included in this analysis. While clinical trial data are based on optimal adherence, studies show that adherence to oral diabetes therapies can range from 38 to 93\% based on different methodologies, with one meta-analysis estimating an adherence rate of $67.9 \%[54,55]$. No realworld data are available on oral semaglutide adherence. Oral semaglutide is to be taken at least 30 min prior to first consumption of food or water and was associated with higher rates of gastrointestinal adverse events than was sitagliptin $100 \mathrm{mg}[22,56]$. Given that both oral semaglutide $14 \mathrm{mg}$ and sitagliptin $100 \mathrm{mg}$ are oral treatments taken daily, adherence was not considered in the analysis. Sixth, this analysis focused on two specific treatment pathways, where basal insulin was added in the second step in therapy. Given that T2DM requires a patient-centric approach, other treatments could be used in patients, with their own efficacy and cost outcomes. Given the limited data on specific combinations of treatment and the desired order of treatment addition, this study uses the best available evidence to represent a potential treatment pathway. Seventh, oral semaglutide may supplant other therapies in addition to sitagliptin, including injectable GLP-1 RAs; this analysis focused on sitagliptin $100 \mathrm{mg}$ because it is also an oral medication. Finally, the analysis makes simplifying assumptions when sizing the target population and estimating relative oral semaglutide $14 \mathrm{mg}$ uptake. However, these assumptions were tested in sensitivity analyses and, even assuming relatively low draw from sitagliptin $100 \mathrm{mg}$ to oral semaglutide $14 \mathrm{mg}$, the overall budget impact for a payer will increase.

\section{Conclusion}

The results indicated that the increase in treatment cost with the use of oral semaglutide $14 \mathrm{mg}$ outweighed the cost savings in other categories. With a 5-year incremental cost of \$US16,562 per patient, oral semaglutide $14 \mathrm{mg}$ increases the budget impact compared with sitagliptin $100 \mathrm{mg}$ for patients with T2DM whose blood glucose level is not under control with metformin treatment. This conclusion held across a variety of scenario analyses.

\section{Declarations}

Funding This study was funded by Merck Sharp \& Dohme Corp., a subsidiary of Merck \& Co., Inc., Kenilworth, NJ, USA. This study is available via Springer Open Choice, with the fee paid for by Merck Sharp \& Dohme Corp., a subsidiary of Merck \& Co., Inc., Kenilworth, NJ USA.

Conflicts of interest Adnan Alsumali, Dominik Lautsch, and Swapnil Rajpathak are employees of Merck Sharp \& Dohme Corp., a subsidiary of Merck \& Co., Inc., Kenilworth, NJ, USA. Glenn Davies was an employee of Merck Sharp \& Dohme Corp., a subsidiary of Merck \& Co., Inc., Kenilworth, NJ, USA, at the time of the study. Andrew Briggs is a director and shareholder of Avalon Health Economics and received compensation from Merck \& Co., Inc. as a consultant for this work. He has also been contracted by Bayer, Eisai, Janssen, Novartis, Sword Health, Amgen, and Daichii Sankyo and received compensation outside of the submitted work. Elizabeth Wehler is an employee of IQVIA, a consulting company that received funding from Merck \& Co., Inc. to conduct the study as well as from other companies. Qianyi Li and Stacey Kowal were employees of IQVIA at the time of the study.

Ethics approval Not applicable.

Consent to participate Not applicable. 
Consent for publication Not applicable.

Availability of data and material The datasets generated during and/or analyzed during the current study are not publicly available as they contain proprietary data but are available from the corresponding author on reasonable request.

\section{Code availability Not applicable.}

Author contributions All authors were involved in developing the model concept and analytic plan. Elizabeth Wehler, Qianyi Li and Stacey Kowal ran the analyses in the CDM and built the budget impact model in Excel. All authors discussed the results and contributed to the final manuscript writing and revisions.

Open Access This article is licensed under a Creative Commons Attribution-NonCommercial 4.0 International License, which permits any non-commercial use, sharing, adaptation, distribution and reproduction in any medium or format, as long as you give appropriate credit to the original author(s) and the source, provide a link to the Creative Commons licence, and indicate if changes were made. The images or other third party material in this article are included in the article's Creative Commons licence, unless indicated otherwise in a credit line to the material. If material is not included in the article's Creative Commons licence and your intended use is not permitted by statutory regulation or exceeds the permitted use, you will need to obtain permission directly from the copyright holder. To view a copy of this licence, visit http://creativecommons.org/licenses/by-nc/4.0/.

\section{References}

1. American Diabetes Association. Facts About Type 2. https:// www.diabetes.org/diabetes-basics/type-2/facts-about-type-2.html. Accessed May 2019.

2. Centers for Disease Control and Prevention. National Diabetes Statistics Report, 2017. Estimates of Diabetes and Its Burden in the United States. https://www.cdc.gov/diabetes/pdfs/data/stati stics/national-diabetes-statistics-report.pdf. Accessed Sept 2019.

3. Bullard KM, Cowie CC, Lessem SE, Saydah SH, Menke A, Geiss LS, et al. Prevalence of diagnosed diabetes in adults by diabetes type-United States, 2016. Morb Mortal Wkly Rep (MMWR). 2018;67(12):359-61.

4. Cohen AJ, Brauer M, Burnett R, Anderson HR, Frostad J, Estep K, et al. Estimates and 25-year trends of the global burden of disease attributable to ambient air pollution: an analysis of data from the Global Burden of Diseases Study 2015. Lancet (London, England). 2017;389(10082):1907-18. https://doi.org/10.1016/s0140 $-6736(17) 30505-6$.

5. Moraga P, Collaborators GCoD. Global, regional, and national age-sex specific mortality for 264 causes of death, 1980-2016: a systematic analysis for the Global Burden of Disease Study 2016. The Lancet. 2017;390(10100):1151-210.

6. Medicine use and spending in the US: a review of 2017 and outlook to 2022. IQVIA Institute for Human Data Science. 2018. https://www.iqvia.com/-/media/iqvia/pdfs/institute-reports/medic ine-use-and-spending-in-the-us-a-review-of-2017-and-outlook-to2022.pdf?_=1588701665780. Accessed May 2020.

7. American Diabetes Association. Economic costs of diabetes in the US in 2017. Diabetes Care. 2018;41(5):917-28.

8. Parker ED, Wittbrodt ET, McPheeters JT, Frias JP. Comparison of healthcare resource utilization and costs in patients with type 2 diabetes initiating dapagliflozin versus sitagliptin. Diabetes Obes Metab. 2019;21(2):227-33. https://doi.org/10.1111/dom.13502.
9. Saundankar V, Ellis J, Allen E, DeLuzio T, Moretz C, Meah Y, et al. Type 2 diabetes mellitus patients' healthcare costs related to inpatient hospitalizations: a retrospective administrative claims database study. Adv Ther. 2015;32(7):662-79. https://doi. org/10.1007/s12325-015-0223-3.

10. American Diabetes Association. Standards of Medical Care in Diabetes. Diabetes Care. 2020;43(S1):S1-212.

11. Cosentino F, Grant PJ, Aboyans V, Bailey CJ, Ceriello A, Delgado V, et al. 2019 ESC Guidelines on diabetes, pre-diabetes, and cardiovascular diseases developed in collaboration with the EASD: The Task Force for diabetes, pre-diabetes, and cardiovascular diseases of the European Society of Cardiology (ESC) and the European Association for the Study of Diabetes (EASD). Eur Heart J. 2020;41(2):255-323.

12. Home P, Naggar NE, Khamseh M, Gonzalez-Galvez G, Shen C, Chakkarwar P, et al. An observational non-interventional study of people with diabetes beginning or changed to insulin analogue therapy in non-Western countries: the Achieve study. Diabetes Res Clin Pract. 2011;94(3):352-63. https://doi.org/10.1016/j.diabr es.2011.10.021.

13. Pantalone KM, Misra-Hebert AD, Hobbs TM, Ji X, Kong SX, Milinovich A, et al. Clinical inertia in type 2 diabetes management: evidence from a large, real-world data. Set Diabetes Care. 2018;41(7):e113-e11414. https://doi.org/10.2337/dc18-0116.

14. Ou S-M, Shih C-J, Chao P-W, Chu H, Kuo S-C, Lee Y-J, et al. Effects on clinical outcomes of adding dipeptidyl peptidase-4 inhibitors versus sulfonylureas to metformin therapy in patients with type 2 diabetes mellitus. Ann Intern Med. 2015;163(9):663-72.

15. Green JB, Bethel MA, Armstrong PW, Buse JB, Engel SS, Garg $\mathrm{J}$, et al. Effect of sitagliptin on cardiovascular outcomes in type 2 diabetes. N Engl J Med. 2015;373(3):232-42. https://doi. org/10.1056/NEJMoa1501352.

16. Husain M, Birkenfeld AL, Donsmark M, Dungan K, Eliaschewitz FG, Franco DR, et al. Oral semaglutide and cardiovascular outcomes in patients with type 2 diabetes. N Engl J Med. 2019;381(9):841-51. https://doi.org/10.1056/NEJMoa1901118.

17. Montvida O, Shaw J, Atherton JJ, Stringer F, Paul SK. Long-term trends in antidiabetes drug usage in the US: real-world evidence in patients newly diagnosed with type 2 diabetes. Diabetes Care. 2018;41(1):69-78. https://doi.org/10.2337/dc17-1414.

18. Rayal AD, Vyas A. National Trends in Diabetes Medication Use in the United States: 2008 to 2015. J Pharm Pract. 2008. https:// doi.org/10.1177/0897190018815048.

19. FDA approves first oral GLP-1 treatment for type 2 diabetes. US Food and Drug Administration. 2019. https://www.fda.gov/newsevents/press-announcements/fda-approves-first-oral-glp-1-treat ment-type-2-diabetes. Accessed 17 April 2020.

20. Pratley R, Amod A, Hoff ST, Kadowaki T, Lingvay I, Nauck M, et al. Oral semaglutide versus subcutaneous liraglutide and placebo in type 2 diabetes (PIONEER 4): a randomised, double-blind, phase 3a trial. Lancet (London, England). 2019;394(10192):3950. https://doi.org/10.1016/s0140-6736(19)31271-1.

21. Rodbard HW, Rosenstock J, Canani LH, Deerochanawong C, Gumprecht J, Lindberg SO, et al. Oral semaglutide versus empagliflozin in patients with type 2 diabetes uncontrolled on metformin: the PIONEER 2 Trial. Diabetes Care. 2019. https://doi. org/10.2337/dc19-0883.

22. Rosenstock J, Allison D, Birkenfeld AL, Blicher TM, Deenadayalan S, Jacobsen JB, et al. Effect of additional oral semaglutide vs sitagliptin on glycated hemoglobin in adults with type 2 diabetes uncontrolled with metformin alone or with sulfonylurea: The PIONEER 3 Randomized Clinical Trial. JAMA. 2019;321(15):146680. https://doi.org/10.1001/jama.2019.2942. 
23. Pieber TR, Bode B, Mertens A, Cho YM, Christiansen E, Hertz $\mathrm{CL}$, et al. Efficacy and safety of oral semaglutide with flexible dose adjustment versus sitagliptin in type 2 diabetes (PIONEER 7): a multicentre, open-label, randomised, phase 3 a trial. Lancet Diabetes Endocrinol. 2019;7(7):528-39. https://doi.org/10.1016/ s2213-8587(19)30194-9.

24. McEwan P, Foos V, Palmer JL, Lamotte M, Lloyd A, Grant D. Validation of the IMS CORE diabetes model. Value in Health. 2014;17(6):714-24.

25. Palmer AJ, Roze S, Valentine WJ, Minshall ME, Foos V, Lurati FM, et al. The CORE Diabetes Model: projecting long-term clinical outcomes, costs and costeffectiveness of interventions in diabetes mellitus (types 1 and 2) to support clinical and reimbursement decision-making. Curr Med Res Opin. 2004;20(sup1):S5-S26.

26. Palmer AJ, Roze S, Valentine WJ, Minshall ME, Foos V, Lurati FM, et al. Validation of the CORE Diabetes Model against epidemiological and clinical studies. Curr Med Res Opin. 2004;20(sup1):S27-S40.

27. Hayes A, Leal J, Gray A, Holman R, Clarke P. UKPDS outcomes model 2: a new version of a model to simulate lifetime health outcomes of patients with type 2 diabetes mellitus using data from the 30 year United Kingdom Prospective Diabetes Study: UKPDS 82. Diabetologia. 2013;56(9):1925-33.

28. Sullivan SD, Mauskopf JA, Augustovski F, Jaime Caro J, Lee KM, Minchin M, et al. Budget impact analysis-principles of good practice: report of the ISPOR 2012 Budget Impact Analysis Good Practice II Task Force. Value Health. 2014;17(1):5-14. https://doi. org/10.1016/j.jval.2013.08.2291.

29. Pratley RE, Eldor R, Raji A, Golm G, Huyck SB, Qiu Y, et al. Ertugliflozin plus sitagliptin versus either individual agent over 52 weeks in patients with type 2 diabetes mellitus inadequately controlled with metformin: The VERTIS FACTORIAL randomized trial. Diabetes Obes Metab. 2018;20(5):1111-20.

30. Roussel R, Duran-García S, Zhang Y, Shah S, Darmiento C, Shankar RR, et al. Double-blind, randomized clinical trial comparing the efficacy and safety of continuing or discontinuing the dipeptidyl peptidase-4 inhibitor sitagliptin when initiating insulin glargine therapy in patients with type 2 diabetes: the CompoSIT-I Study. Diabetes Obes Metab. 2019;21(4):781-90.

31. Zinman B, Aroda VR, Buse JB, Cariou B, Harris SB, Hoff ST et al. 985-P: Oral semaglutide as add-on to insulin in T2D: PIONEER 8. Diabetes. 2019;68(Supplement 1).

32. Billings LK, Doshi A, Gouet D, Oviedo A, Rodbard HW, Tentolouris N, et al. Efficacy and safety of IDegLira versus basal-bolus insulin therapy in patients with type 2 diabetes uncontrolled on metformin and basal insulin: the DUAL VII randomized clinical trial. Diabetes Care. 2018;41(5):1009-166.

33. Fritsche A, Larbig M, Owens D, Haring HU, group Gs. Comparison between a basal-bolus and a premixed insulin regimen in individuals with type 2 diabetes-results of the GINGER study. Diabetes Obes Metab. 2010;12(2):115-23. https://doi.org/10.11 11/j.1463-1326.2009.01165.x.

34. Medi-Span Price Rx Database [database on the Internet]. https:// pricerx.medispan.com/IngredientName.aspx. Accessed Dec 2019.

35. Institute for Clinical and Economic Review. Oral semaglutide for type 2 diabetes: effectiveness and value. 2019. https://icer-revie w.org/wp-content/uploads/2019/04/ICER_Diabetes_Final-Evide nce-Report_120919.pdf. Accessed Aug 2020.

36. US Food and Drug Administration. Online Label Repository. https ://labels.fda.gov/. Accessed Dec 2019.

37. National Institute for Health and Care Excellence (NICE). Canagliflozin, dapagliflozin, and empagliflozin monotherapy for treating type 2 diabetes. In: Assessment report—produced by Warwick
Evidence October 4, 2015. https://www.nice.org.uk/guidance/ TA390/documents/assessment-report. Accessed Sept 2019.

38. Schütt M, Kern W, Krause U, Busch P, Dapp A, Grziwotz R, et al. Is the frequency of self-monitoring of blood glucose related to long-term metabolic control? Multicenter analysis including 24500 patients from 191 centers in Germany and Austria. Exp Clin Endocrinol Diabetes. 2006;114(07):384-8.

39. ADW Diabetes: Diabetes supplies [database on the Internet]. https ://www.adwdiabetes.com/. Accessed July 2019.

40. Centers for Medicare and Medicaid Services. Durable Medical Equipment, Prosthetics, Orthotics, and Supplies (DMEPOS) Fee Schedule 2019. https://www.cms.gov/Medicare/Medicare-Fee-forService-Payment/DMEPOSFeeSched/DMEPOS-Fee-Schedule. html. Accessed July 2019.

41. Centers for Medicare and Medicaid Services. Clinical laboratory fee schedule. 2019. https://www.cms.gov/Medicare/MedicareFee-for-Service-Payment/ClinicalLabFeeSched/Clinical-Labor atory-Fee-Schedule-Files-Items/19CLABQ3. Accessed July 2019.

42. Centers for Medicare and Medicaid Services. Physician fee schedule. 2019. https://www.cms.gov/apps/physician-fee-schedule/searc h/search-criteria.aspx. Accessed July 2019.

43. Yeaw J, Halinan S, Hines D, DeLozier A, Perez M, Boye M, et al. Direct medical costs for complications among children and adults with diabetes in the US commercial payer setting. Appl Health Econ Health Policy. 2014;12(2):219-30.

44. Foos V, McEwan P. Conversion of hypoglycemia utility decrements from categorical units reflecting event history into event specific disutility scores applicable to diabetes decision models. Value Health. 2018;21:S223.

45. Blough DK, Hubbard S, McFarland LV, Smith DG, Gambel JM, Reiber GE. Prosthetic cost projections for servicemembers with major limb loss from Vietnam and OIF/OEF. J Rehabil Res Dev. 2010;47(4):387-402.

46. US Census Bureau. Table 2, 2020 Projection. 2017. https://censu s.gov/data/tables/2017/demo/popproj/2017-summary-tables.html. Accessed 26 Feb 2020.

47. Centers for Disease Control and Prevention. Morbidity and Mortality Weekly Report (MMWR) 2018. 2018.

48. Soric MM, Moorman JM, Boyle JA, Dengler-Crish CM. Prevalence and predictors of metformin prescribing in adults with type 2 diabetes mellitus: a national cross-sectional study. Pharmacotherapy. 2016;36(7):715-22. https://doi.org/10.1002/phar.1772.

49. Hunt B, Hansen BB, Ericsson A, Kallenbach K, Ali SN, Dang-Tan $\mathrm{T}$, et al. Evaluation of the cost per patient achieving treatment targets with oral semaglutide: a short-term cost-effectiveness analysis in the United States. Adv Ther. 2019;36(12):3483-93. https:// doi.org/10.1007/s12325-019-01125-y.

50. Rodbard HW, Lingvay I, Reed J, de la Rosa R, Rose L, Sugimoto $\mathrm{D}$, et al. Semaglutide added to basal insulin in type 2 diabetes (SUSTAIN 5): a randomized, controlled trial. J Clin Endocrinol Metab. 2018;103(6):2291-301. https://doi.org/10.1210/jc.201800070.

51. Fei Y, Tsoi MF, Kumana CR, Cheung TT, Cheung BMY. Network meta-analysis of cardiovascular outcomes in randomized controlled trials of new antidiabetic drugs. Int J Cardiol. 2018;254:291-6. https://doi.org/10.1016/j.ijcard.2017.12.039.

52. Yang DY, He X, Liang HW, Zhang SZ, Zhong XB, Luo CF, et al. Comparative outcomes of heart failure among existent classes of anti-diabetic agents: a network meta-analysis of 171,253 participants from 91 randomized controlled trials. Cardiovasc Diabetol. 2019;18(1):47. https://doi.org/10.1186/s12933-019-0853-x.

53. Zhuang XD, He X, Yang DY, Guo Y, He JG, Xiao HP, et al. Comparative cardiovascular outcomes in the era of novel antidiabetic agents: a comprehensive network meta-analysis of 
166,371 participants from 170 randomized controlled trials. Cardiovasc Diabetol. 2018;17(1):79. https://doi.org/10.1186/s1293 3-018-0722-z.

54. Polonsky WH, Henry RR. Poor medication adherence in type 2 diabetes: recognizing the scope of the problem and its key contributors. Patient Prefer Adherence. 2016;10:1299-307. https:// doi.org/10.2147/PPA.S106821
55. Iglay K, Cartier SE, Rosen VM, Zarotsky V, Rajpathak SN, Radican L, et al. Meta-analysis of studies examining medication adherence, persistence, and discontinuation of oral antihyperglycemic agents in type 2 diabetes. Curr Med Res Opin. 2015;31(7):128396. https://doi.org/10.1185/03007995.2015.1053048.

56. Rybelsus semaglutide tablets prescribing information. 2020. https ://www.novo-pi.com/rybelsus.pdf. Accessed Aug 2020.

\section{Affiliations}

\section{Elizabeth Wehler ${ }^{1}$. Dominik Lautsch ${ }^{2}$. Stacey Kowal ${ }^{1}$. Glenn Davies ${ }^{2}$ - Andrew Briggs ${ }^{3}$. Qianyi Li ${ }^{1}$. Swapnil Rajpathak ${ }^{2} \cdot$ Adnan Alsumali $^{2}$}

1 IQVIA, 1 IMS Drive, Plymouth Meeting, PA 19462, USA

2 Merck \& Co., Inc., Kenilworth, NJ, USA

\author{
London School of Hygiene \& Tropical Medicine, London, \\ UK
}

